\title{
Effect of Sports on all Kinds of Illness such as Osteoporosis and Obesity
}

\author{
Shi Ying*
}

\author{
School of Physical Education Science, Nantong University, Nantong, China
}

\begin{abstract}
With the population of old people is ever-increasing in the world. Osteoporosis, as one of the serious disease affecting the living quality of the old, has attracted wide concern among scholars in various countries. Consequently, seeking more effective methods to prevent and treat osteoporosis has become a hot research topic. Research findings have proved that proper physical exercise can slow down the pace of osteoporosis and promote people's physical and psychological health. At the same time, there are more and more obese men all over the world. Prevention and treatment of obesity have been becoming one of the focuses of human healthy problem. Aerobic exercise and adjustment of diet have been accepted extensively. The metabolism of carbohydrate and fat, which are the main energy resources, vary with different diet and exercise intensity. Therefore, studying the change of carbohydrate and lipid metabolism in obese man during endurance exercise is a principal task to prevent and treat obesity.
\end{abstract}

Keywords: Aerobic exercise, carbohydrate metabolism, obesity, osteoporosis, physical exercise, psychological health.

\section{INTRODUCTION}

As population of old ages are increasing in the world, osteoporosis has become one of the important disease that impact on the quality of old people's life. Because of its high incidence and high mortality rates due to fracture, so that countries are making great efforts to support research osteoporosis. The results showed that osteoporosis prevention is more important than treatment, appropriate exercise intensity of anti-gravity exercise can effectively increase the peak bone mass that occurs with age slows osteoporosis [1].

Osteoporosis, a prevalence bone disease of occult progress, is now a worldwide health issue with common concern. As the world population of aging process continues to accelerate, osteoporosis is rapidly becoming a global public health problem. Its high incidence not only significantly reduce the quality of human life, but also causing enormous economic burden on society. So the world are vigorously osteoporosis prevention and treatment work.

Currently, There are three main methods to prevent osteoporosis, namely nutrition therapy, drug therapy and exercise therapy, and the effect of exercise therapy is often overlooked. According to the latest study found that the impact of exercise on bone mineral density $(40 \%)$ far exceeds the affect of bone metabolism hormones related to calcium and vitamin $\mathrm{D}$ on bone mineral density (3\% to $10 \%$ ). Long-term scientific physical exercise can maintain and improve bone mineral density, increase muscle strength, improve balance ability of human motion, reducing the risk of wrestling, thereby reducing the incidence of fractures due to osteoporosis caused by appropriate exercise can alleviate pain caused by osteoporosis, can increase the activities of daily living. Exercise therapy is a simple, easy, safe, economical and durable efficacy and other characteristics, can identify with and accepted by the people, therefore, regular physical exercise is the best way to prevent and treat osteoporosis [2].

Osteoporosis, an age-associated disease that occures with the increasing of age, is one of the most common metabolic bone disease in old people. Characterized by decreased bone mass, bone tissue fibers structural changes, increased bone fragility and increased risk of fracture. Elderly associated intestinal calcium absorption is considered to connected with bone loss and senile osteoporosis. Lack of exercise is also a reason to accelerate osteoporosis in the elder people. Osteoporosis Osteoporosis is divided into primary and secondary osteoporosis.

Massage, the precious heritage of Chinese medicine, with its simple, without any special equipment, just a different way to act on the body, to improve physical function, reduce fatigue and treat disease. It is the fact that we all known. It is not only play a very important role in terms of injury prevention, but also in the correcting of players' behavior before the game, dysfunction after the game, elimination of fatigue, improvement of athletic ability. Therefore, to learn and master massage techniques teaching, training and competition have certain practical significance [3].

\section{THE INTRODUCTION OF ISTEOPOROSIS AND OBESITY}

Osteoporosis is a disease characterized by reduced bone mass, bone micro-structural damage, leading to increased bone fragility and fracture prone. The factors of osteoporosis disease is multiple, and related to hormone regulation, nutrition, physical factors, genetic and immunological 
Table 1. Oxygen uptake under four power compared with the measured value formula speculation.

\begin{tabular}{|c|c|c|c|c|c|c|}
\hline $\begin{array}{c}\text { Power } \\
\text { (W) }\end{array}$ & Measured Values & $\begin{array}{c}\text { The Estimated } \\
\text { Value of the For- } \\
\text { mula }\end{array}$ & $\begin{array}{c}\text { Differences with } \\
\text { the Measured } \\
\text { Values }\end{array}$ & $\begin{array}{c}\text { SEE } \\
(\mathrm{ml} / \mathrm{min})\end{array}$ & $\begin{array}{c}E \\
(\mathrm{ml} / \mathrm{min})\end{array}$ & $\mathbf{r}$ \\
\hline 30 & $734.08 \pm 34.64$ & 807.74 & $73.66 \pm 21.30$ & 23.90 & 76.60 & $0.72 .$. \\
\hline 60 & $1053.97 \pm 40.90$ & $1133.14 \pm 21.62$ & $79.17 \pm 29.20$ & 28.04 & 84.23 & $0.73 .$. \\
\hline 90 & $1378.90 \pm 57.19$ & $1457.88 \pm 20.88$ & $78.98 \pm 38.14$ & 30.77 & 87.48 & $0.84 .$. \\
\hline 120 & $1747.19 \pm 63.10$ & $1778.97 \pm 19.74$ & $31.78 \pm 19.21$ & 42.23 & 57.78 & $0.74 .$. \\
\hline
\end{tabular}

abnormalities, bone metabolic risk factors in a negative balance, reduce the amount of lead to bone matrix and calcium.

Diagnosis of osteoporosis include physical diagnosis (measuring bone density), (measured biochemical indicators of bone minerals, bone resorption and bone formation) bone histomorphometry diagnostics (morphological bone structure and content) and biochemical diagnostics [4]. Multiple human studies measuring bone density, it non-invasive, simple, and more advanced method is dual-energy X-ray absorptiometry. Metrological examination of bone tissue can be quantified osteoblasts and osteoclasts, to understand the structure of bone or connectivity, but invasive examination, used for animal experiments. Animal studies can also used for bone mechanical index determination.

Obesity is a condition caused by excessive accumulation of body fat, being considered as an easily found significant, complex metabolic disorder, it is a physiological process that can affect the normal function of the entire body. Determination indicator of obesity that commonly used is BMI, body fat percentage (Fat $\%$ ) and the degree of obesity $[5]$.

What is considered obese? Current internationally accepted indicator of obesity is the body mass index of disputes (BMI):

$$
B M I=\text { weight }(\mathrm{kg}) / \operatorname{height}\left(\mathrm{cm}^{2}\right)
$$

World Health Organization regard BMI $>25 \mathrm{~kg} / \mathrm{m}^{2}$ and $>30 \mathrm{~kg} / \mathrm{m}^{2}$ as overweight and fat in 1998. Compared with Europeans, Asians will appear metabolic diseases at lower BMI. Thus, World Health Organization revised the standard of obesity for the physiological and morphological characteristics of the Asia-Pacific region residents, regard the $\mathrm{BMI}>23 \mathrm{~kg} / \mathrm{m}^{2}$ and $>25 \mathrm{~kg} / \mathrm{m}^{2}$ as overweight and obesity.

\section{COMPARATIVE STUDY ON OBESE FEMALES' BICYCLE ERGOMETER}

Effective exercise to lose weight depends on the scientific and reasonable exercise prescription, and its core is a reasonable load strength and load. Sports physiology study found that oxygen uptake is an important index of exercise intensity.

Subjects were completed increasing load exercise load power car with $0 \mathrm{~W}$ onwards, every three minutes increments $30 \mathrm{~W}, 120 \mathrm{~W}$ ends a movement to power the car speed of 60 rev / min. Found oxygen uptake take subjects under each load and the existing three power car motion oxygen uptake prediction equation estimated value comparison, the American College of Sports Medicine (ACSM) for healthy people to establish oxygen uptake prediction equation.

$$
\left(\mathrm{ml} \cdot \mathrm{kg}^{-1} \cdot \mathrm{min}^{-1}\right)=\text { Power / weight } \times 10.8+7
$$

Latin establish a suitable formula to calculate oxygen uptake young women:

$$
\left(\mathrm{ml} \cdot \min ^{-1}\right)=\operatorname{Power}(W) \times 1.6+\{[3.5 \times \text { weight }(\mathrm{kg})]+205\}
$$

Latin established the oxygen uptake prediction equation that young men and women are applicable:

$$
\left(\mathrm{ml} \cdot \min ^{-1}\right)=\operatorname{Power}(W) \times 11.0+[6.7 \times \text { weight }(\mathrm{kg})]
$$

Test its accuracy and create a new formula: The results show that for normal healthy people build ACSM oxygen uptake prediction equation found in formula and the estimated value of obese women with the power of $30 \mathrm{~W}$, $60 \mathrm{~W}, 90 \mathrm{~W}, 120 \mathrm{~W}$ under comparison, the four oxygen uptake under a load of speculation formula values are higher than the measured value, the oxygen uptake mean difference $32 \sim 79 \mathrm{ml} / \mathrm{min}$ range, under all four power difference was significant $(\mathrm{P}<0.05)$ [6]. SEE range between $24-42 \mathrm{ml} / \mathrm{min}, \mathrm{E}$ values range between $58-87 \mathrm{ml} / \mathrm{min}$, the estimated value and the measured value formulas correlation coefficient at each power reaches 0.72 or more (Table $\mathbf{1}$ ).

Young men and women test results power car oxygen uptake prediction equation of motion: Latin for the young men and women to establish estimated oxygen uptake in $30 \mathrm{~W}, 60 \mathrm{~W}, 90 \mathrm{~W}, 120 \mathrm{~W}$ under the formulas of the estimated value formula and obesity compared with middle school girls found under power, oxygen uptake formula under the estimated value of each load higher than Found, and the differences were statistically significant $(\mathrm{P}<0.05)$, the average difference between oxygen uptake $36-76 \mathrm{ml} / \mathrm{min}$ range [7]. SEE range between $26-38 \mathrm{ml} / \mathrm{min}$, E values range between $60-85 \mathrm{ml} / \mathrm{min}$, oxygen uptake formula estimated value and the measured value of the correlation coefficient reached 0.67 at four power above (Table 2).

ACSM Ergometer oxygen uptake prediction equation though revised, but still very broadly applicable objects, so that when an object is specific to a certain gender, there are training history, obesity and other groups, the accuracy of the formula is very limited, different groups of people 
Table 2. Subjects heart rate during exercise magnitude comparator.

\begin{tabular}{|c|c|c|c|c|}
\hline \multirow{2}{*}{ Time } & \multicolumn{2}{|c|}{ Normal Group } & \multicolumn{2}{|c|}{ Obese Group } \\
\hline & $40 \% \mathrm{VO}_{2 \max }$ & $65 \% \mathrm{VO}_{2 \max }$ & $40 \% \mathrm{VO}_{2 \max }$ & $65 \% \mathrm{VO}_{2 \max }$ \\
\hline Be quiet & 0 & 0 & 0 & 0 \\
\hline Motion instantly & $11.33 \pm 7.48$ & $7.56 \pm 6.17$ & $12.25 \pm 3.75$ & $10.38 \pm 6.81$ \\
\hline 10 minutes & $36.22 \pm 11.85$ & $77.89 \pm 11.21$ & $39.63 \pm 7.63$ & $68.38 \pm 9.22$ \\
\hline 20 minutes & $37.78 \pm 10.47$ & $82.44 \pm 10.27$ & $42.50 \pm 9.00$ & $75.63 \pm 8.47$ \\
\hline 30 minutes & $38.22 \pm 11.36$ & $84.56 \pm 8.94$ & $43.00 \pm 12.25$ & $77.25 \pm 7.50$ \\
\hline 40 minutes & $37.89 \pm 10.99$ & $87.11 \pm 9.43$ & $43.13 \pm 11.16$ & $79.88 \pm 8.66$ \\
\hline 50 minutes & $38.78 \pm 9.70$ & $86.00 \pm 10.00$ & $43.00 \pm 11.00$ & $79.38 \pm 9.22$ \\
\hline 60 minutes & $35.56 \pm 9.95$ & $88.33 \pm 9.12$ & $44.75 \pm 12.75$ & $80.25 \pm 10.31$ \\
\hline
\end{tabular}

different exercise intensity will be a different error [8]. Obesity is an important factor in the impact of oxygen uptake movement, engaged in the same load power car movement oxygen uptake in obese women than normal women, the relatively low efficiency of power sports car, there are also significant differences between different levels of obesity.

\section{EFFECT OF EXERCISE ON VARIOUS DISEASES}

\section{Exercise Therapy Mental Illness}

Anxiety is what we often say that the feelings of irritability, anger manifested as anxiety, worried something terrible seems to happen, often accompanied by headache, dizziness, palpitation, shortness of breath, take the sweating and other physical discomfort. If long-term state of anxiety, tension, angry state, can lead to high blood pressure, coronary heart disease, bronchial asthma and other diseases, serious harm to health and quality of life.

Treatment: (1) select some interesting or strong interest for the treatment of patients with project activities, such as badminton, volleyball, basketball, swimming, hiking, and tourism. (2) World Health Organization has listed as one of tai chi exercise cardiac rehabilitation program, which has enhanced the ability of self-control, to stabilize the restlessness role. (3) Exercise enough relaxation exercises to be done, let the body fully relaxed. Relaxation is the key to the treatment.

Depression: the performance of appetite, lazy, apathy, loss of interest, and often self-blame, severe recurrent thoughts of suicide occur, and even suicidal behavior. If a person's character is always repressed anger and frustration, and often triggers the disease.

Treatment: (1) Selecting a skill collective project for the treatment of active items: such as soccer, volleyball, basketball, etc., to improve the excitability and spirit of cooperation with the emotions of others, so that patients experience after the joy of success, Improving excitability. (2) It is used to say, three times a week, every 30 minutes for eight weeks of walking or jogging, suffering from severe depression may have a significant reduction in sensory and physical symptoms of depression and self-esteem, health improved markedly, (3) People can be self-cultivation of Taoism "Yoga", and seek my heart a special balance.

\section{Effect of Exercise on Osteoporosis}

Effect of exercise on bone mass in different ages of people: Minors reaction forces on bone tissue (gravity and muscle tension) load is through modeling and remodeling to have completed, bone metabolism in life constantly changing, children, young people in the strong period of growth and development of bone density will continue to increase until the peak value reached a peak bone density around age 30 years or younger [9].

Exercise load role in the developmental stages of human bones to increase its volume so as to achieve a higher bone mineral density peaks on the future prevention of osteoporosis plays a significant role. Bone conformed to adulthood basically completed, and absorption and reconstruction of the bone last a lifetime. With increasing age, the number of bones in the apoptosis of bone cells gradually reduce the number of bone cells.

\section{Effect of Exercise on Obesity}

Comparison of Physiological Index: Heart rate and blood pressure, cardiovascular function is a reflection of the easiest targets, maximal oxygen uptake $\left(\mathrm{VO}_{2 \max }\right)$ is a reflection of the body's aerobic capacity of common indicators. Heart rate $(p<0.01)$ in obese group quiet and diastolic blood pressure $(p<0.05)$ were significantly higher than the control group mean, $\mathrm{VO}_{2 \max }$ was significantly lower than the control group $(\mathrm{P}<0.001)$; systolic blood pressure was not significantly different, but have increased in the obese group trend, and standard deviation is large (Table 3 ).

Compare Heart Rate: (1) In both load intensity ( $40 \%$ and $65 \%$ VO2max $)$ during exercise $(\mathrm{P}<0.001)$ and recovery $(\mathrm{P}<0.01)$, obese heart rate were significantly higher than the normal group. (2) In the beginning of the phase obese and normal heart rate the same trends are rapidly rising, 10 minutes into the plateau, and obesity was significantly higher 
Table 3. Obese and normal resting heart rate and blood pressure comparison.

\begin{tabular}{|c|c|c|}
\hline Index & Normal Group & Obese Group \\
\hline \hline Heart rate (beats/min) & $62.44 \pm 3.26$ & $81.88 \pm 5.63^{* *}$ \\
\hline $\mathrm{SBP}(\mathrm{mmHg})$ & $108.22 \pm 3.80$ & $116.00 \pm 9.50$ \\
\hline Diastolic blood pressure $(\mathrm{mmHg})$ & $69.33 \pm 1.78$ & $78.75 \pm 6.56^{*}$ \\
\hline $\mathrm{VO}_{2 \max }(\mathrm{ml} / \mathrm{kg})$ & $45.73 \pm 2.93$ & $29.01 \pm 2.21^{* * *}$ \\
\hline
\end{tabular}

Note: $* \mathrm{P}<0.05, * * \mathrm{P}<0.01, * * * \mathrm{P}<0.001$
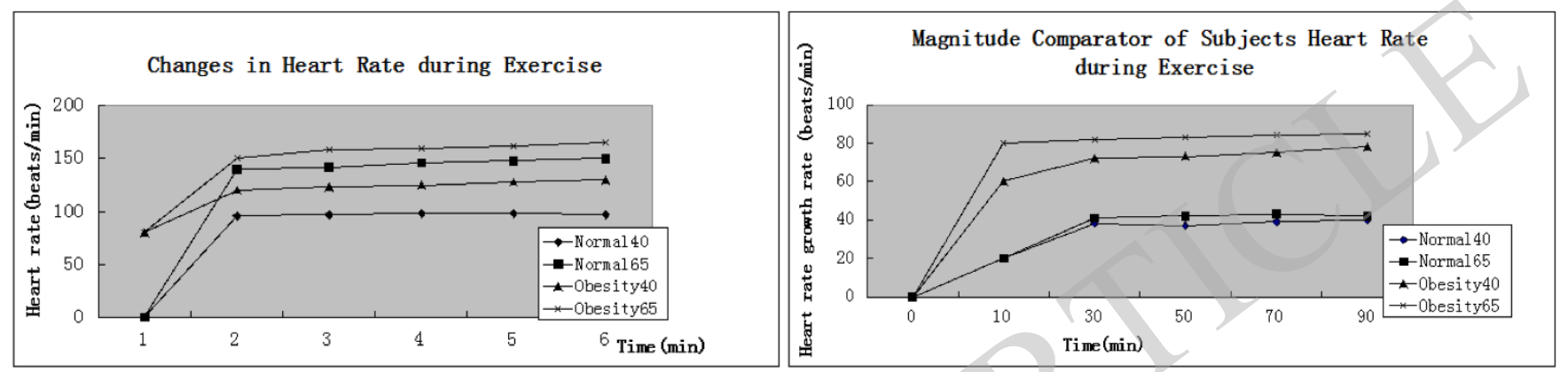

Fig. (1). Results on four test function.

than the normal group $(\mathrm{P}<0.05)$; the growth rate of obesity in heart rate compared with the normal group, $40 \% \mathrm{VO} 2 \mathrm{max}$ exercise significantly greater than $65 \% \mathrm{VO} 2 \max$ movement. (3) at $40 \% \mathrm{VO} 2 \mathrm{max}$ during exercise, normal heart rate in the late plateau decreased, while there is still upward trend in the obese group. (4) After exercise, obesity, decrease in heart rate is less than the normal group, heart rate recovery is slow, at $65 \% \mathrm{VO} 2 \mathrm{max}$ this phenomenon is particularly evident in sports $(\mathrm{P}<0.01)$.

The results suggest that obese due to excessive fat accumulation, cardiovascular functions are restricted, functional decline and reduce the ability to adapt to the movement stimuli; as exercise intensity increases, the body's response to strengthen the cardiovascular, slow recovery after exercise [10].

\section{CONCLUSION}

Long-term scientific movement is one of the effective methods of prevention and treatment of osteoporosis, exercise can increase bone mass in adolescent bone so that a higher peak bone mass achieved, the role of adult bone is to preserve bone mass primarily to reduce bone loss. Movement as a measure of prevention and treatment of osteoporosis, in addition to physiology should be evaluated, it must also carry out a comprehensive evaluation of their respect psychology, economics, society, and thus more fully and effectively implement its function and value for the benefit of human society. Numerous studies have confirmed that children from the elderly through exercise until you can maintain and improve bone structure. But so far not been able to find the most effective campaign in the most effective way to increase bone density and maintain bone density. But what We can confirm is sports do really have a very important influence on all kindes of illness.

\section{CONFLICT OF INTEREST}

The author confirms that this article content has no conflict of interest.

\section{ACKNOWLEDGEMENTS}

This work is supported by 2013 scientific research project of Nantong University (2013NTKY021), Natural Science Foundation of of Nantong University (2013NTNSF069).

\section{REFERENCES}

[1] E. Avlonitou, E. Georgiou, G. Douskas, and A. Louizi, "Estimation of body composition in competitive swimmers by means of three different techniques," Int J. Sports Med. vol. 18, no.5, pp.363-368, 1997.

[2] S.N. Blair, "Evidence for success of exercise in weight loss and control," Ann Intern Med. vol. 119, no. 7, pp. 702-706, 1993.

[3] S. Bourrin, C. Genty, S. Palle, C. Gharib, and C. Alexandre, "Adverse effects of strenuous exercise: a densitometry and histomorpho metric study in the rat," $J$ Appl Physiol. Vol. 76, no.5, pp.1999 2005, 1994.

[4] D. P.C. van Aggel-Lei, W. H. M. Saris, G. B. Hul. And M. A. van Baak, "Short-term effect of weight loss with or without low intensity exercise training on fat metabolism in obese men," Am J Nutr., vol. 73, pp.523-531, 2001.

[5] H. Salvesen, A.G. Johansson, P. Foxdal, L. Wide, K. Piehl-Aulin, and S. Ljunghall, "Links Intact serum parathyroid hormone levels increase during running exercise in well-trained men," Calcif Tissue Int, vol. 54, no.4, pp.256 261, 1994.

[6] N. Schonfeld-Warden, and C.H. Warden, "Pediatric obesity: An overview of etiology and treatment," Pediatr Clin North Am., vol. 44, no.2, pp. 339-361, 1997.

[7] M.E.J. Lean, T.S. Hans, and J.C. Slidell, "Impairment of health and quality life in people with large waist circumference," Lancet., vol. 351, pp.853-856, 1998.

[8] L. A. Pruitt, R.D. Jackson, R.L. Bartels, and H.J. Lehnhard, "Weight-training effects on bone mineral density in early postmenopausal women," J. Bone Miner Res, no.7, pp.179-185, 1992. 
[9] K. A. Grove, and B.R. Londeree, "Bone density in postmenopausal women: High impact vs low impact exercise," Med Sic Sports Exerc, no.24, pp.1185-1190, 1992.
[10] Z. Peng, J. Tuukkanen, and H.K. Väänänen, "Exercise can provide against bone loss and prevent the decrease in mechanical strength of femoral neck in ovariectomized rats," Journal of Bone and Mineral Research, vol. 9, no.10, pp.1559, 1994.

Received: June 10, 2015

Revised: July 29, 2015

Accepted: August 15, 2015

(C) Shi Ying; Licensee Bentham Open.

This is an open access article licensed under the terms of the (https://creativecommons.org/licenses/by/4.0/legalcode), which permits unrestricted, noncommercial use, distribution and reproduction in any medium, provided the work is properly cited. 